\title{
Дихателни нарушения по време на сън (ДНВС) - хирургични методи на лечение
}

\author{
Б. Банова, Д. Петкова \\ Клиника по оториноларингология \\ Клиника по белодробни болести \\ Сектор по медицина на съня МБАЛ "Св. Марина" - Варна, \\ Медицински университет - Варна
}

Въведение

Медицината на съня е интердисциплинарно медицинско направление за диагностика и разрабоване на методи за лечение на дихателните нарушения по време на сън. Това определя засиления интерес на лекарите - пулмолози и оториноларинголози към дадения проблем. В резултат от многобройни научни разработки през 1976 г. се появява окончателната формулировка на симптомокомплекса на патологично нощно преустановяване на дишането (1) наречен „синдром на обструктивна апнея-хипопнея“" (OSAS, OSAHS).

Най-характерни и често наблюдавани прояви на този симптомокомплекс са колапсьт на гълтачния отдел на горните дихателни пътища (ГДП), повишеното съпротивление към въздушния поток, хиповентилационни дихателни нарушения с различна степен на проявление.

OSAS е широко разпространена сред населението патология. По данни на различни автори честотата на това нарушение варира от $2 \%$ сред жените до $4 \%$ сред мъжете в трудоспособна възраст (2). Този симптомокомплекс достига своето максимално разпространение сред лица с наднормено тегло, мъже и възрастни (3).

OSAS съществено понижава продължителността на живот и нарушава неговото качество. Повишената дневна сънливост, промяната на типа личност, нощното хъркане и сексуалните разтройства стават причина за индивидуални и социални конфликти на пациентите. Често наблюдаваните при пациенти с OSAHS артериална хипертония и нарушение на сърдечния ритъм значително повишават риска от внезапна смърт по време на сън (3). 
Хъркането като проява на нарушено дишане засяга $60 \%$ от мъжете и $40 \%$ от жените във възрастовата група 60-65 години (1). Това определя и значимостта от терапевтичното повлияване на този чест проблем. В процеса на диагностично уточняване се включват търсене на OSAS и клиничен преглед на носа, околоносните кухини назо-и орофаринк$\mathrm{ca}$, устната кухина и ларинкса. Ако пациентьт се оплаква от хронично затруднение на назалното дишане или ако в рамките на OSAS е затруднено впасването на назалната маска поради обструкция на носните ходове, успешно биха могли да се прилагат оперативни интервенции на носа или на околоносните кухини. При патологични промени на небните дъги, увулата или при извънредно големи тонзили днес наред с традиционните оперативни интервенции се прилагат и $\mathrm{CO}_{2}$-лазер и апарати за радиочестотни интервенции. Анатомично разположената назад основа на езика, макроглосията или дисгнатията успешно могат да се коригират с помощта на хирургични интервенции.

Известно е, че индуцираната по време на сън екстраторакална обструкция на дихателните пьтища в областта на орофаринкса е решаващият патогенетичен механизъм за развитието както на обструктивна сънна апнея в детска възраст, така и при възрастни. В детската възраст, както и в периода на растеж могат да се установят морфологични предразполагащи фактори за развитието на ДНВС. От голямо значение са уголемените тонзили, аденоидните вегетации, които могат да се отстранят оперативно, което довежда до пълно обратно развитие на OSAS, както и на свързаната с това клинична симптоматика. С изчезването на фарингеалната обструкция децата могат отново да спят спокойно, като дневната сънливост, неспокойствието и нарушението на концентрацията се понижават, а успехът в училище се повишава. Нарушенията на съня са свързани с нарушение в продукцията на растежен хормон, което забавя растежа. След осъществяване на успешна оперативна интервенция в рамките на няколко месеца тези нарушения претьрпяват обратно развитие. При възрастни уголемените тонзили също могат да доведат до развитие на OSAS. Други морфологични предразполагащи фактори, които могат да се подложат на хирургична интервенция, са вродените дисплазии на лицевия череп дисгнатии, които са обект на хирургична корекция от специалистите по лицево-челюстна хирургия.

Интактното носно дишане оказва стабилизиращо действие на дишането по време на сън. При нарушено носно дишане прийомите на назална вентилация биха могли да се прилагат със затруднение, или при определени обстоятелства да доведат до някои коригируеми усложнения. Поради това е препоръчително при пациенти с диагностицирани ДНВС преди стартирането на неинвазивна вентилация да се осъществи консултация със специалист УНГ с оглед преценка на ГДП. Концепцията за лечение при пациенти с хъркане се отличава значимо от тази за лечение на пациенти с OSAS. Тъй като хабитуалното хъркане не се счита за заболяавне, при пациентите с подобни проблеми става дума за извършване на факултативно лечение, което пациентът сам трябва да пожелае. В съображение в тези случаи влиза минимално-инвазивната хирургия. Предприетото лечение трябва да доведе до редукция на интензитета и продължителността на хъркане, като в идеалния случай трябва да го преодолее. Често се предпочита интервенция с по-малък риск от усложнения, която обаче е свързана с по-мальк шанс за успех. С времето обаче хабитуалното хъркане може да се развие до манифестен синдром на OSA. Поради това осьществяването локално хирургично лечение не трябва да прави невъзможно въвеждането на вентилаторно лечение. Така Mortimore (1996) (4) показва, че резекцията на мекото небце може да доведе до значимо отзяване на маската и изтичане на въздух от нея още при налягане от 7 мм воден стълб, подавано от СРАР машината. Ако при пациент бъде установена OSAS, то той трябва да бъде подложен на адекватно лечение, което да осигури преодоляването на апнеите, хипопнеите, микросъбужданията и кислородните десатурации във всички стадии на съня и във всички позиции.

\section{Индикации за оперативно лечение}

Още преди 40 години Kuhlo и Doll (5) във Франкфурт доказват, че познатият и използван отдавна прийом на трахеостомията може да доведе до обратно развитие на симптомите на сънна апнея, познати по това време като синдром на Pickwick. Оперативните интервенции в областта на ГДП имат основно адювантно значение или могат да бъдат средство на терапевтичен избор. По този начин операциите на ГДП се предприемат, за да подобрят назалното дишане, често адювантно, да подобрят комплаянса на назалното вентилаторно лечение или на интраоралните помощни средства, дори да направят възможно изобщо лечението с тези средства. При пациенти със затльстяване, тежка сънна апнея и непоносимост към лечение с постоянно позитивно налягане (СРАР), при които с оглед лечение е необходимо да се оперира фаринксьт, в редки случаи се 
налага трахеостомия за осигуряване на безопасност на дихателните пътища, докато отокът на меките тъкани бъде оптимално повлиян. За да се индицира специфична операция при пациенти с ДНВС, е необходимо да се познава точната анатомия и функция на ГДП. В рамките на клинично ендоскопско изследване трябва да се дефинират аномалиите, които се нуждаят от корекция и които биха могли да бъдат коригирани. Няма стандартен тип операция, която да може да бъде препоръчвана на всички пациенти.

\section{Топична диагностика на обструкцията}

Дълго време провеждането на оперативни интервенции за лечението на пациенти c OSAS бе немислимо, преди да бъде дефинирана точно локализацията на фарингеалния колапс, за да може да бъде осъществена оперативна интервенция. Клинично-ендоскопските изследвания в будно състояние, осыществени с помощта на ригидна или флексибилна ендоскопия в условията на седиране, видио-ендоскопията осъществена по време на сън, цефалометрията и компютърната томография, както и ядрено-магнитният резонанс са инструменталните изследвания, които визуализират мястото на колапс, респ. механизма на колапс и повишават нивото на успех. Значителен недостатьк на тези изследвания е, че те дават представа само за кратък период от време в будно състояние или в условия на седиране (ендоскопия, цефалометрия, CT,MRI) или в условията на сън (ендоскопия, СT, MRI).

Тъй като както колапсът на ГДП, така и механизмите на колапс се различават за всяка нощ и за различните стадии на съня, както показват зависимост от позицията в леглото, тези методи не могат да бъдат надеждни за изводи относно нарушенията през цялата нощ.

\section{Ефективност от лечението}

Въпреки че по-голямата част от оперативните интервенции се предприемат за лечение на пациенти с OSAS и непоносимост към лечението със CРAP, резултатите от оперативното лечение би трябвало да се сравнят с контролна група, която е провеждала алтернативно лечение. До този момент само 8 контролирани проучвания, които третират ефекта от увулопалатофарингопластика (UPPP), лазерасоциирана увулопластика (LAUP) или радиофреквентна терапия (RFT) в основата на езика с участието на общо 421 пациенти с OSAS, покриват критериите за включване в ревю, публикувано в базата Cochrane през 2005 година ,surgery for obstructive sleep apnea“. Като контролна група служат пациенти, третирани със СРАР или орални шини, както и такива с плацебо RFT. Всички останали студии не са взети под внимание поради липсата на контролна група. В това ревю, подготвено съобразно изискванията на медицината, базирана на доказателствата, не се препорьчва използването на оперативни интервенции за лечение на неселектирани пациенти с OSAS, поради хетерогенността на оценените методи и поставените цели за лечение (6). До момента липсва общоприета и единна дефиниция за успех от лечението. По-голяма част от изследванията се базират на данните от полиграфски и полисомнографски анализ. Първичният параметър, който е основна цел на лечението, е апнея-хипопнея индексът (АНI). Наложена е мярка за достигането на определен апнея-хипопнея индекс с минимум 50\% редукция, който да се намира под една абсолютна постоперативна стойност. В англо-американската литература за клинична ефективност се приема спадането на АНI под 20/час сън. В по-голямата част от клиничните проучвания се намират данни за относителния дял на успешните в контекста на горните норми оперирани пациенти. Данни от редица проучвания сочат обаче,че независимо от избрания метод на оперативна интервенция броят на успешно лекуваните пациенти в рамките на първите две години след оперативната интервенция се понижава.

Данни за промените в сатурацията, продължителността на хъркането, респираторните микросъбуждания (RERA), са вторични параметри, които са отговорни за качеството и количеството на съня и отговарят за успеха на терапията. Субективните параметри, които са свързани с дневната симптоматика и качеството на живот при оперативни интервенции, по правило показват положителни резултати. Те корелират обаче ненадеждно с полисомнографските данни. Данните относно дълготрайното влияние на оперативните интервенции върху заболеваемостта и смъртността от OSAS са недостатъчни и противоречиви. При компенсирано хъркане липсват все още критерии, които определят успеха от терапията.

\section{Оценка на оперативните методики, прилагани за лечение на OSAS}

При деца с OSAS и големи тонзили тонзилектомията или тонзилотомията като първо средство на избор заема водещо място. При възрастни с отстояние между тонзилите под 5мм тази оперативна интервенция също може да доведе до успешни резултати, дори и при липсата на контролирани проучвания. Трахеотомията е много ефективен 
метод за лечение на OSAS, но днес тя се прилага само при най-тежките случаи, при които са изчерпани всички останали методи за лечение. Радиофреквентната аблация на мекото небце и лазер-асоциираната увулопалатофарингопластика не могат да бъдат препоръчани като средство на избор за лечение при пациенти с OSAS поради липсата на доказана ефективност от тяхното приложение при OSAS. Радиофреквентната аблация на корена на езика може да доведе при около 1/3 от пациентите с лека OSA до редукция на дихателните нарушения с минимум 50\% и $\mathrm{AHI}<15 /$ час сън. Най-общо операциите в областта на меките тъкани на ГДП, изключая случаите на обструкциите на ГДП в будно състояние от хиперплазиралите аденоиди и тонзили в лечението на OSAS, оперативният подход трябва да се обсъжда едва тогава, когато липсва ефект от приложението на лечение с позитивно налягане. Радиофреквентната и лазерасоциираната увулопалатофарингопластика се използват често като средство на избор за лечение на пациенти с обикновено хъркане, след като OSAS е изключена след извършване на PSG изследване. Две контролирани проучвания, при които хъркането е обективно измерено, показват липсата на обективни различия по отношение на силата на генерирания шум при хъркане преди и шест месеца след оперативната интервенция. При анализ на данните от субективната оценка на брачните партньори на оперираните не се установява преустановяването му в болшинството от случаите. Дълготраен успех от прилаганото лечение не е документиран.

\section{Аденотомия, тонзилектомия и тонзилотомия}

По правило увеличението на фарингеалната тонзила, или т.нар. аденоидни вегетации, и на небните сливици води до обструкция на назо-, респ. орофаринкса и хипофаринкса и се среща много често при малки деца, деца в училищна възраст и по-рядко при възрастни. Аденотомията и тонзилектомията са рутинни оперативни прийоми за всеки специалист оториноларинголог. Всичките изброени оперативни методики водят до значимо разширяване на фарингеалния лумен и като такива са най-успешното оперативно средство на избор за лечение на пациенти с OSAS след трахеотомията както при деца, така и при възрастни. С помощта на тези оперативни интервенции OSAS при показани пациенти може да бъде преодоляна според данните от серийни проучвания $(7,8,9,10)$.
Терапевтичният ефект при деца е значим, независимо от това дали е извършена тонзилектомия или тонзилотомия, както показват данните от рандомизирано проучване на Hultcranz и сътр. 2005 (11). За резултатите от ефективността на тонзилотомията при възрастни с OSAS досега липсват данни. Хъркащи деца с типични симптоми и констилация за OSAS и аденотонзиларна хиперплазия, както и възрастни пациенти със сънна апнея и междутонзиларно пространство по-малко от 5 мм са показани въз основа на високия дял на успеха от интервенцията за първично отстраняване на тонзилите. При деца в предучилищна възраст по правило се осъществява комбинирано тонзилектомия заедно с аденотомия. Полисомнографското изследване при здрави деца с категорична клинична картина и обективно изследване може да бъде избегнато. Във всички останали случаи е абсолютно необходимо извършването на PSG изследване с оглед поставяне на диагноза от специалист по медицина на съня. За извършването на оперативните интервенции липсват абсолютни контраиндикации, но при наличието на данни за нарушение в системата на кръвосъсирване, двойна увула, субмукозно цепнато меко небце и задна бразда на твърдото небце трябва да се подхожда внимателно и да се предпочита тонзилотомия пред тонзилектомия.

На успешните резултати от тонзилектомията по отношение на лечението на OSAS се противопоставят високата пери- и постоперативна болестност в лицето на болкова симптоматика, затруднено гълтане, както и риск от кървене и по-дълъг период на хоспитализация. Много експерти днес не препоръчват първичното приложение на тонзилотомия при пациенти с OSAS поради факта, че в $10 \%$ от случаите след тонзилотомията е налице повторна тонзиларна хиперплазия, която налага необходимостта от повторна тонзилектомия. След тонзилектомия се достига веднага до подобряване на дишането и на съня, което в случаи на аденотомия се постига едва след една до две седмици. Резултатите от аденотомията могат да се проявят и едва месец след оперативната интервенция. При 90\% от всички показани пациенти след операцията не се налага допълнително лечение. Деца със сънна апнея остават и след успешна адено-тонзилектомия във висок риск за развитие на обструктивна сънна апнея (12). Родителите респ. пациентите трябва да бъдат активно разпитвани относно наличие на симптоматика в детските години и при необходимост да бъдат уточнявани диагностично в център за изследване на съня. 


\section{Оперативни интервенции за подобряване на назалното дишане}

Още през 16 век Levinus (1581) предполага, че дишането през устата в позиция по гръб води до неободряващ сън. Поради това много рано са предприети опити симптомите на нарушено дишане по време на сън и техните последици да бъдат предотвратявани посредством операции на носа. В края на 19. век се съобщава за подобряване на вигилантността при осем от 40 пациенти, които са претьрпяли оперативна интервенция в областта на носа (Wells 1898). Под понятието операция на носа в този смисъл се разбират всички оперативни интервенции, които се извъриват върху носните раковини, назалната преграда и околоносните кухини, входа на носа и назалната пирамида с цел нормализиране на увреденото назално дишане. Тези оперативни интервенции представят най-честите УНГ интервенции. Докато операциите на носните раковини по правило се осъществяват под локална анестезия и в амбулаторни условия, то тези на носната преграда, околоносните кухини и на външния нос изискват винаги обща анестезия и стационарен престой. Специфичните индикации, осъществяването, провеждането, следоперативното наблюдение и усложненията са описани в специализираната литература. Поради необходимостта от често налагащата се назална тампонада носното дишане е така затруднено за пьрвите една до три нощи след оперативната интервенция и дори го прави невъзможно, че пациентът диша през устата. Използването на тампонада с дихателни тръбички често е недостатъчно поради високото съпротивлвние към въздушния поток и е невъзможно избягването на дишането през устата. При пациенти с обикновено хъркане или при такива с леко изразена сънна апнея тези ранни постоперативни проблеми остават без последици, но при пациенти с тежко изразена сънна апнея и/или налични придружаващи белодробни и сърдечносъдови заболявания може да се достигне до последващо обостряне на дихателното и/или сърдечното заболяване. Поради това при подобни пациенти е препоръчителен и наложителен постоперативен мониторинг за първите шест часа след оперативната интервенция. Като допълнение към това вентилацията със СРАР може да бъде стартирана веднага след екстубирането през лицева маска. Ако при това се стигне до кървене във фаринкса, вентилацията трябва да бъде преустановена веднага, за да се предотврати аспирация на кръв. След риносептопластика назална маска би могла да се въведе за лечение едва след 6 месеца от оперативната интервенция поради опасността от разместването на носната пирамида. Подобреното назално дишне води до повишаване на относителния дял на дълбокия сън и понижаване на времето, прекарано в будно състояние и араузал индекса, независимо от обема на преоперативно документираното нарушение на назалното дишане. Дневната сънливост се понижава сигнификантно, както измерена посредством ESS скора за сънливост, така и посредством MSLT-теста, според различни проучвания. При пациенти с хабитуално, обикновено хъркане въз основа на използване на въпросници и визуална аналогова скала се достига до преодоляване на хъркането в $40 \%$ от пациентите след операция на носа. При OSAS оперативните интервенции в областта на носа има резултат само при единични пациенти. Във всички случаи едноседмичен терапевтичен тест с отбъбващ назален спрей би довел до подобряване на назалното дишане и промяна в оплакванията, предизвикани от ДНВС и промяна в полиграфските, респ. полисомнографски резултати, респ. комплаянса към лечението, който би трябвало да се очаква при пациентите и е прост и безопасен метод.

Първична индикация за оперативно лечение от позиция на медицината на съня би трябвало да се предприеме в случаите, при които при пациента е налице затруднено носно дишане, отбъбване на лигавицата след приложение на назален спрей, както и морфологично нарушение при рино-ендоскопското изследване, което може да бъде коригирано при операция на външния и/или вътрешния нос. Подобрението на съня, дишането и дневните симптоми представя позитивния ефект от ринологична гледна точка, който прави операцията необходима. Вторична индикация за оперативно лечение се налага при пациенти с налична протрузионна шина на долната челюст или стартирана вентилация по време на сън по повод налично ДНВС, които те не могат да използва пълноценно поради обективно компроментирано назално дишане. Операциите за подобряване на назалното дишане служат за подобрение на комплаянса към терапията. Те са основна съставна част от оперативните методи за лечение при пациенти с ДНВС.

\section{Трахеотомия}

Трахеотомията е оперативна интервенция, която осъществява директна връзка между трахеята и повърхността на шията. При осъществяването на трахеотомия фаринксьт и ларинксьт като потенциални рискови локализации за колапс на ГДП се 
заобикалят. Всяка форма на ДНВС в резултат от екстраторакална обструкция в този смисъл може да бъде преодоляна при използване на този метод на лечение.Трахеотомията е метод за лечение на OSAS, който успешно е бил въведен от Kuhlo et al.през 1969 година (5). Днес, поради свързаните с нея медицински и физиологични усложнения, тя служи или като крайно средство на избор при пациенти, при които останалите методи за лечение са изчерпани, или се използва за сигурност на дихателните пьтища в първите дни до седмици след големи операции по повод OSAS. При деца тя е средство на избор като мост до осъществяването на оперативна корекция на малформация, която е отговорна за ДНВС. Освен нарушения в кръвосъсирването за извършването на трахеостомията липсват други контраиндикации.

Трахеята се отваря на височината на втория до четвъртия трахеален пръстен и се зашива с кожата. Трахеостомата в началото се стабилизира посредством трахеална канюла. Пункционна трахеотомия не е уместна при пациенти със сънна апнея в случаите на необходимост от дълготрайно лечение, т.к. без наличието на канюла пункционната трахеостома ще се затвори бързо спонтанно.

През нощта пациентьт носи или трахеалната канюла, през която диша, или я сваля. През деня той носи или канюла, посредством която може да говори, или покрива трахеостома. И в двата случая оперативната интервенция води до ограничаване на качеството на живот на пациента и може да го инвалидизира. При адипозни пациенти наред с гореизложените проблеми може да се достигне до трудно заздравяване на раната от трахеостомата дори и в случаите, при които интраоперативно е било възможно осъществяването на резекция на мастна тъкан и реализирането на свободна от налягане мукокутанна анастомоза. Посредством трахеостомата OSAS може да бъде преодоляна при всички категории пациенти, както това е показано в най-голямото публикувано ретроспективно проучване, включващо серия от 79 пациенти (Thatcher et al. 2003 (13)).

\section{Други методи Радиофреквентна терапия (RFT)}

При този метод става дума за интерстициална апликация на високофреквентен променлив ток посредством изработени за тази цел и локализация специални иглови електроди. Активните електроди могат да бъдат моно- или биполярни. Лигавицата, лежаща върху мястото на апликация, е пощадена от провежданата интервенция. Обра- зуваната интерстициално топлина довежда до коагулация на белтьците с последвашо образуване на съединителна тъкан, което е свързано с локално упльтняване и редукция на тьканта.При средно тежка и тежка OSAS RFT не бива да бъде прилагана поради липсата на клинична ефективност. При лекостепенна OSAS тя е средство на избор при наличие на анатомични абнормалитети и може да се осъществи върху корена на езика или тонзилите, респ. при хъркане и хиперплазия на носните раковини, върху мекото небце и носните раковини. Пациентите трябва да са информирани,че подобна интервенция има успех само в $50 \%$ от случаите. Пациенти с подлежаща едностранна пареза на n.hypoglossus ca контраиндицирани за подобни интервенции в областта на основата на езика, тъй като една подобна термична интервенция би могла да доведе до пълна имобилизация на останалите нерви на езика. При хронична тонзиларна инфекция този метод на третиране на небните тонзили не се препоръчва поради възможността от улесняване развитието на интратонзиларни абсцеси в областта на участъците на некроза. Интервенцията в областта на носните раковини и мекото небце се осъществява в условията на локална анестезия, в областта на корена на езика и тонзилите с допълнително седиране и петдневен профилактичен антибактериален курс на лечение. Оптимално е осигуряването на допълнителна дезинфекция на лигавицата.

По време на интервенцията иглата се фиксира върху хиперплазиралата тъкан и системата се активира. Дълбочината на проникване на активния електрод се определя от неговия строеж. Големината на лезията се определя или автоматично посредством задаване на време,-импеданс- или температурна индикация, или изисква активно завършване на процедурата, определено от оператора. Процедурата може да се повтори след 2 месеца или по-късно, за да се повиши степента на успех. Като максимум са наложени 4-6 терапевтични процедури. Този брой обаче би могъл да варира въз основа на променените терапевтични схеми в рамките на следващите години.

Постоперативните болки са по-малки, сравнени с останалите оперативни интервенции. Много важно е да се обърне внимание на изразения оток на меките тъкани в рамките на първите 24 часа от осъществената оперативна интервенция, поради което може да се наложи стационарно наблюдение. Освен това в $2 \%$ от случаите може да се достигне до усложнения като язви на лигавицата, възпаление на корена на езика и продължителни дисфагии (14). В единични случаи може да се 
достигне до лезии на n.hypoglossus. Постоперативната заболеваемост в областта на тонзилите и основата на езика се редуцира благодарение на антибиотична профилактика. Доказателства за клинична ефективност на метода при пациенти с лека OSAS са налице само при интервенции върху корена на езика и комбинацията с третиране на мекото небце. Данни от проспективни студии сочат, че при използването на метода OSA може да бъде редуцирана при $1 / 3$ от пациентите, като AHI се редуцира с по-вече от $15 \%$ и при изходна стойност $<15 \%$ (14). Какво означава постигнатият от интервенцията ефект в контекста на кардиоваскуларните последици на OSAS и дневната сънливост, налична при пациентите, все още е неясно. Качеството на живот и времето за реакция могат да се подобрят сигнификантно при приложението на комбинирано лечение в сравнение с плацебо, при липса на сигнификантно различие с пациентите, поставени на лечение с СРАР. Проучване на Woodson и сьтр. (15) показва, че само СРАР терапията води до понижаване на АНІ, като липсва сигнификантна разлика между плацебо и радиофреквентната терапия. До този момент проучванията, касаещи ефективността на RFT, са били провеждани само при пациенти с AНI под 50 респ. ВМI < 35 така, че за ефективност при пациенти с изразена сънна апнея, респ. затлъстяване, изводи не могат да се направят. Загубата на ефект след 1 година от осъществяването на RFT е описана. За ефектите на RFT на мекото небце върху хъркането е проведено двойносляпо плацебоконтролирано проучване за период от 6 месеца с помощта на визуална аналогова скала (16). Обективното измерване на дълготрайните ефекти обаче трябва да се проучи допълнително. За приложението върху носните раковини са валидни същите критерии за ефективност, както и при останалите прийоми, свьрзани с подобряване на назалното дишане.

\section{Лазер асистирана увулопалатопластика (LAUP)}

Лазер асистираната увулопалатопластика е въведена в края на 80-те години първоначално като амбулаторен метод, осъществяван под локална анестезия при пациенти с ДНВС. Предпоставка за развитието му е избягването на тонзилектомията и зашиването на небните дъги, както и възможността с помощта на лазера да се оперира безкръвно. Поради това методът включва инцизия на параувуларни лезии на небните дъги и скъсяване на увулата.Той трябва да доведе до скъсяване и укреп- ване на мекото небце, което трябва да редуцира веларните вибрации. Докато първоначално инцизиите са били твърде радикални и са обхващали изрязване на мускулатурата на мекото небце, днес този радикален подход е изоставен. Лазер асистирана увулопалатопластика е средство на избор при пациенти с хабитуално, неусложнено хъркане и $\mathrm{BMI}<30 \kappa г / \mathrm{M}^{2}$, с дълга увула, дълбоко разположена задна дъга на мекото небце и малки или липсващи тонзили. Операцията не трябва да се извършва при хора, чиито професии са свързани с говорене или пеене или такива с незатворено твърдо небце. Наличието на сънна апнея с малки изключения е контраиндикация за тази интервенция.

За извършване на интервенцията днес се използват наред с $\mathrm{CO}_{2}$-лазер и радиофреквентни игли като режещи инструменти. След анестезия на мекото небце задната небна дъга се инцизира параувуларно до ръба на предната небна дъга и увулата се скъсява до нивото на m. uvulae. Не се налага прилагането на антибактериална профилактика. В първите 10 постоперативни дни е необходимо да се помисли за подходяща аналгезия, т.к. инцизията на лигавицата предизвиква изразена болка. В последващите седмици раневата повърхност може да заздравее, образувайки неконтролиран цикатрикс, като в редки случаи може да се достигне до изтегляне на небната дьга и до стеноза на назофаринкса. Освен това след лазер асистирана увулопалатопластика при $1 / 5$ от пациентите може да се явят парестезии, аспирация и наличие на различни респираторни шумове. Клиничната ефективност на лазер асистираната увулопалатопластика при пациенти c OSAS не е установена при сравнение както с нелекувани пациенти с OSAS, така и в сравнение с пациенти с осъществена UPPP (17).

\section{Заключение}

Проблемът с хъркането и обструктивните дихателни нарушения е комплексен и многопластов. $(18,19)$ Заедно с патологичните морфологични промени и различните рискови фактори при пациентите с подобни нарушения е на лице генетична предиспозиция. При това се достига в зависимост от фазата на съня до индивидуална загуба на тонус на гълтателната и дъвкателната мускулатура. Поради това успехът от хирургична интервенция често не може да бъде оценен и дефиниран. Лечението на обикновеното хъркане се различава значимо от това при OSA, и т.к. то не е заболяване, при него се използват факултативни методи за лечение, които пациентьт трябва да предприеме. Осьществяваните операции за подобряване на 
назалното дишане често са адювантна мярка, с оглед осигуряване на по-добър комплаянс към приложението на назалната вентилация. Въпреки че хирургичното лечение на обструктивните синдроми на сънна апнея се осъществява при пациенти, които не понасят вентилацията, резултатите от оперативното лечение се сравнят с тези от вентилаторната терапия и други контролни групи. (20, 21, 22) Към момента липсват достатъчно доказателства в подкрепа на широкото използване на хирургичното лечение на неселектирани пациенти с OSA (Sundarm et al. 2005 (23)).
1. Guilleminault C, Eldridge FL, Tilkian A, Simmons FB, Dement WC. Sleep apnea syndrome due to upper airway obstruction: a review of 25 cases. Arch Intern Med. 1977 Mar; 137(3): 296-300

2. Young T, Palta M, Dempsey J, Skatrud J, Weber S, Badr S.The occurrence of sleep-disordered breathing among middle-aged adultsN Engl J Med. 1993 Apr 29;328(17):1230-5.

3. Fletcher EC, Brown DL.Nocturnal oxyhemoglobin desaturation following tracheostomy for obstructive sleep apnea.Am J Med. $1985 \mathrm{Jul}$; 79(1): 35-42.

4. Mortimore IL, Bradley PA, Murray JA, Douglas NJ; Uvulopalatopharyngoplasty may compromise nasal CPAP therapy in sleep apnea syndrome. Am J Respir Crit Care Med. 1996 Dec; 154(6 Pt 1): 1759-62.

5. Kuhlo W, Doll E, Franck MC Erfolgreiche Behandlung eines PickwickSyndroms durch eine Dauertrachealkanuele, Dtsch.Med. Wochenschrift 94: $1286-1290$

6. Sundarm S, Bridgman SA, Lim J, Lasserson TJ, Surgery for obstruktive sleep apnoea. The Cochrane Database of Systematic Reviews. Issue 4.Art.N: CD 001004.pub2.DOI:10.1002/14651858. CD001004.pub2., 2005 ,

7. Nieminen P, Tolonen U, Löppönen H.Snoring and obstructive sleep apnea in children: a 6-month follow-up study.Arch Otolaryngol Head Neck Surg. 2000 Apr; 126(4): 481-6.

8. Nieminen P, Löppönen H, Väyrynen M, Tervonen A, Tolonen U.Nasalance scores in snoring children with obstructive symptoms.Int J Pediatr Otorhinolaryngol. 2000 Jan 30; 52(1): 53-60

9. Verse T, Maurer JT, Pirsig W.Effect of nasal surgery on sleep-related breathing disorders. Laryngoscope. 2002

10. Verse T, Pirsig W. Long-term outcome and new developments in the field of sleep apnea. IILaryngorhinootologie. 2000 Nov; 79(11): 692-3.

11. Hultcrantz E, Linder A, Markström A.; Long-term effects of intracapsular partial tonsillectomy (tonsillotomy) compared with full tonsillectomy.Int J Pediatr Otorhinolaryngol. 2005 Apr; 69(4): 463-9. Epub 2004 Dec 30.

12. Tasker C, Crosby JH, Stradling JR.Evidence for persistence of upper airway narrowing during sleep, 12 years after adenotonsillectomy. Arch Dis Child. 2002 Jan; 86(1): 34-7.

13. Thatcher GW, Maisel RH.;The long-term evaluation of tracheostomy in the management of severe obstructive sleep apnea. Laryngoscope. 2003 Feb; 113(2): 201-4 